\title{
PETRI NET MODEL OF SUPPLY VESSEL CONSUMPTION AS FUNCTION OF THE NATURE OF THE BUSINESS AND THE STATE OF THE WIND AND SEA
}

\author{
Toni Meštrović, Danko Kezić, Ivica Pavić, SrđanVukša \\ University of Split (Croatia)
}

\begin{abstract}
The state of prices and the development of a given economy depends largely on the gas and oil industry. Every day the gas and oil industry is growing and there is a growing need for platforms. In order for the platforms to pump gas and oil from the seabed unhindered, it is necessary to supply the platform which is done by supply vessels. In this paper, with the help of Petri nets and the tool "Yasper", the dynamic process of supply and operation of supply vessels is simulated. Simulation is depending on the wind and wave conditions and the type of work that the supply vessel performs in cooperation with the platform. Input data are: Sea state, wind state, fuel consumption, type of vessel operation, distance from the mainland and the number of daily departures of the vessels from the port. The paper presents a model with discrete events in the process of supplying the platform, starting from the port and going out to sea until the work around the platform is completed and returning to the port. The report can provide information on the usability of the vessels and the approximate cost of the supply vessels on a voyage from port to the platform and back.

Keywords: supply ships; supply platforms; process model; sea state; wind state; petri net; Yasper tool
\end{abstract}

\section{Introduction}

The oil and gas industry is one of the most important industries in the world and has a huge impact on all other industries, whether positive or negative. Every day the technology of offshore gas and oil exploration in the sea is advancing and there are more and more platforms producing gas and oil located at a greater distance from land. In order for platforms to operate continuously and explore and produce oil and gas, they must be supplied daily with all necessary materials, cargo, water, and supplies for the crew. The most convenient way to supply them is with the help of supply vessels that bring everything they need from the mainland, which is one of the most expensive factors in the logistical supply chain in the oil and gas industry. 
Normally, the supply vessels are rented and not owned by the oil companies. The oil companies themselves choose the number of supply vessels they need for a particular platform and decide on the type and duration of the rental contract. The position of the platform and the size of the platform itself, as well as the nature of the work to be done on the platform, dictate certain parameters, and it is on the basis of these parameters that the size and capability of the supply vessel is selected. For oil companies as users of these supply vessels, one of the most important issues is the daily consumption and usability of the supply vessels. In this paper, we present a model of the platform supply process with supply vessels created in Petri nets using the Yasper tool. Based on input data, the model shows the usability of ships depending on the type of ships and their approximate consumption in terms of the type of work they perform around the platform and the distance of the platform from the land that the ship has to cross in navigation.

\section{The working process of supply vessels}

Supply vessels are one of the most important factors in the crude oil supply chain. They sail between the port and the platform on a daily basis and supply the platforms. They differ in size, engine power and intended use, with the main subdivisions being Anchor Handling Supply Vessels (AHTS) and Platform Supply Vessels (PSV).

AHTS vessels (Figure 1) have three basic tasks, namely, supplying the platform with the necessary cargo, towing barges with the platform equipment and lifting the platform anchor when it needs to be deployed. They are classified according to the power of the winch motor which raises and drops (moves) the anchors from the platform in search of gas and oil.

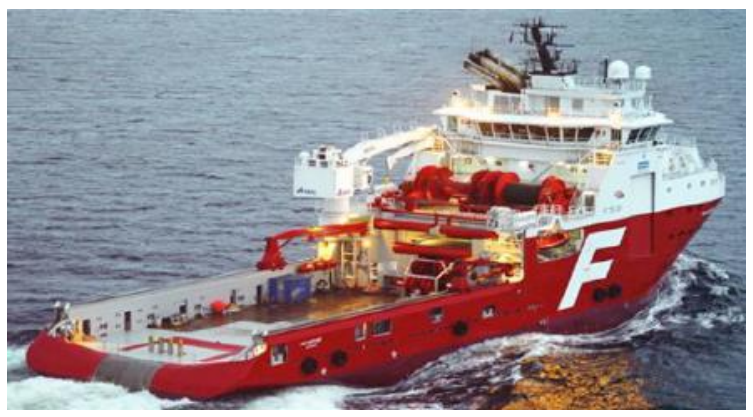

Figure 1. Anchor Handling Supply Vessel (AHTS) ${ }^{1)}$

PSV vessels (Figure 2) do not have the ability to move the anchors as they do not have a winch. They are classified by the length of the main deck where the necessary cargo is stored and transported to the platform. Below deck, both types of 
vessels carry in tanks the potable water, fuel, and liquid chemicals that the platform needs for normal operations.

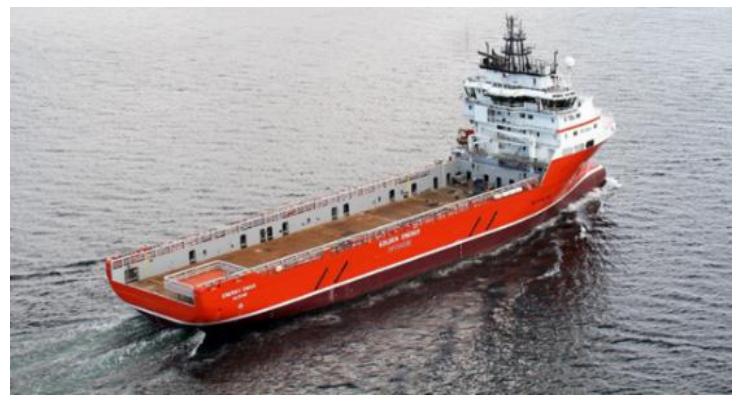

Figure 2. PSV vessel ${ }^{2)}$

At the end of 2019, there were 3388 supply vessels, 1768 AHTS vessels and 1620 PSV vessels in the world, of which about $35 \%$ were not fully utilized but were on a dead berth, and in 2020 the percentage of ships on a dead berth is much higher due to the corona and the collapse of the global economy ${ }^{3)}$. Supply vessel rental rates vary and depend on the state of the world economy. The average daily hire price for AHTS was $£ 15,427$ in 2020 , which is $35 \%$ lower than in 2019 . For PSV vessels, the average daily rental price was $£ 5,806$, which is $48 \%$ less than the previous year ${ }^{4)}$.

\section{Petri net and Yasper tool}

Petri nets are a graphical method for modeling dynamical systems for the purpose of analyzing their behavior under various conditions and are named after their inventor Carl Adam Petri. Petri nets allow the definition and simulation of various states and processes in the observed system, as well as the description of the flow of information and objects through the system. The definition a Petri net consists of a place, a process step, and an arc. Arcs go from place to process step or vice versa, never between places or between process steps. The main purpose of Petri nets is to model, simulate, and analyze dynamic systems with discrete events (DEDS) (Ling 2001).

Petri nets are applicable in various fields such as computer networks, communication systems, production systems (Zurawsk et al. 1994), control systems (Camurri et al. 1993), chemistry, traffic processes, mathematics, etc. Petri nets can represent states and events that cause transitions from one state to another, and the conditions that must be satisfied for a transition from one state to another to occur can be expressed explicitly (Reisig et al. 1998).

The formalism of Petri nets has evolved considerably since its original solution (Petri 1962) (Murata 1989). Various extensions to the basic definition of Petri nets 
have been developed to support a wide range of applications. Some of the more significant extensions are colored Petri nets (Jensen 1997), Timed Petri nets (Wang 1998), inhibitor arc Petri nets, priority Petri nets, etc.

Yasper is a tool to specify and execute a model of a discrete - step process ${ }^{5)}$. The Yasper tool is based on Petri nets, is available, and is visually appealing because of the colors used in modeling, so that the user can get a better idea of the model itself. Emitters and collectors are yellow, places are white or yellow (insensitive or sensitive), process steps are green and the step of choice (XOR element) is brown (Figure 3). Within the process step itself, time and cost can be included. At the end of the simulation, the individual costs and time of the simulation can be considered from the starting points to the end points, i.e. from the emitter to the collector.

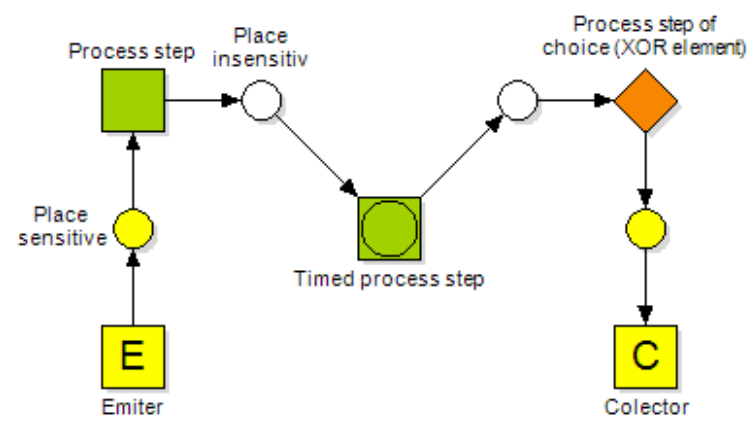

Figure 3. Yasper model of petri net with places, process step and arcs Source: Author - Yasper

\section{Model of vessels operation process for platform supply}

From the prices listed in the previous chapter, it can be seen that the rental price varies and is highly dependent on the situation in the world economy. In order to find out approximately how much is spent daily on supply vessels, we have created a model using the Yasper tools in Petri nets. (Figure 4)

Model for checking the wind and sea state in the port

In the first part of the model (Figure 5.), the time period for the emission of the event within the emitter E is determined. After the emission from the "emitter" we come to the process step "wind condition check", where the state of the wind in the port is selected. In the "wind condition check" process step, the wind condition is specified by a percentage and we have three places. If the wind is greater than $9 \mathrm{bf}$, the event is stopped because the wind is not suitable for sailing (storm). If the wind is less than $3 \mathrm{bf}$, the wind is favorable and the event continues (the supply vessel ready to sail). If the wind is between 3 and 9 bf, the event continues with a new process step "Sea condition check" in which the sea condition is checked. Within 


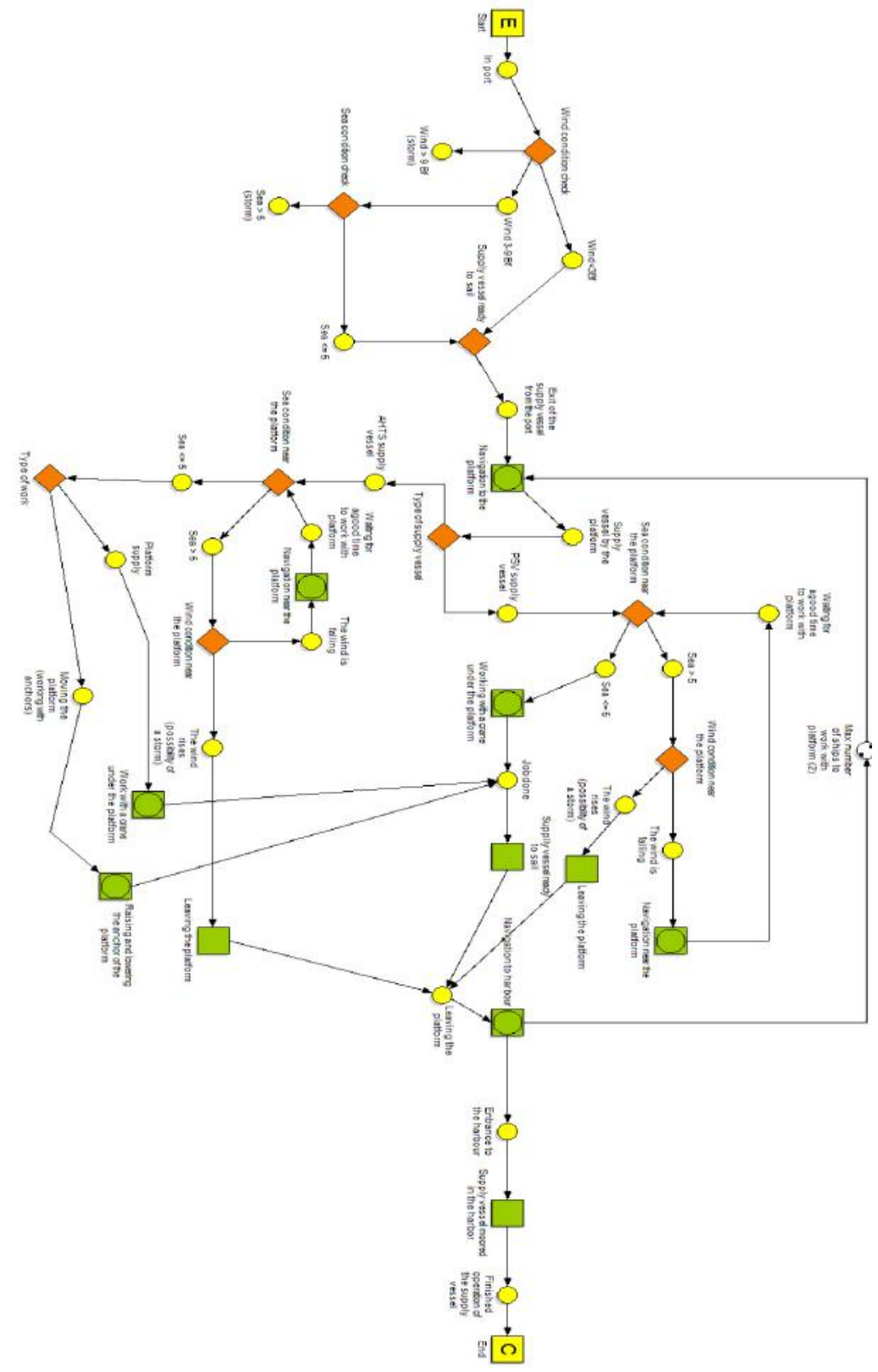

Figure 4. Model of the supply vessels operating process Source: Author - Yasper 
the process step, the sea condition is set as a percentage and we have 2 places. If the sea state is greater than 5, the event is stopped because the sea is not suitable for sailing. If the sea condition is less than or equal to 5 , the weather is favorable and the event continues (the supply vessel is ready to sail).

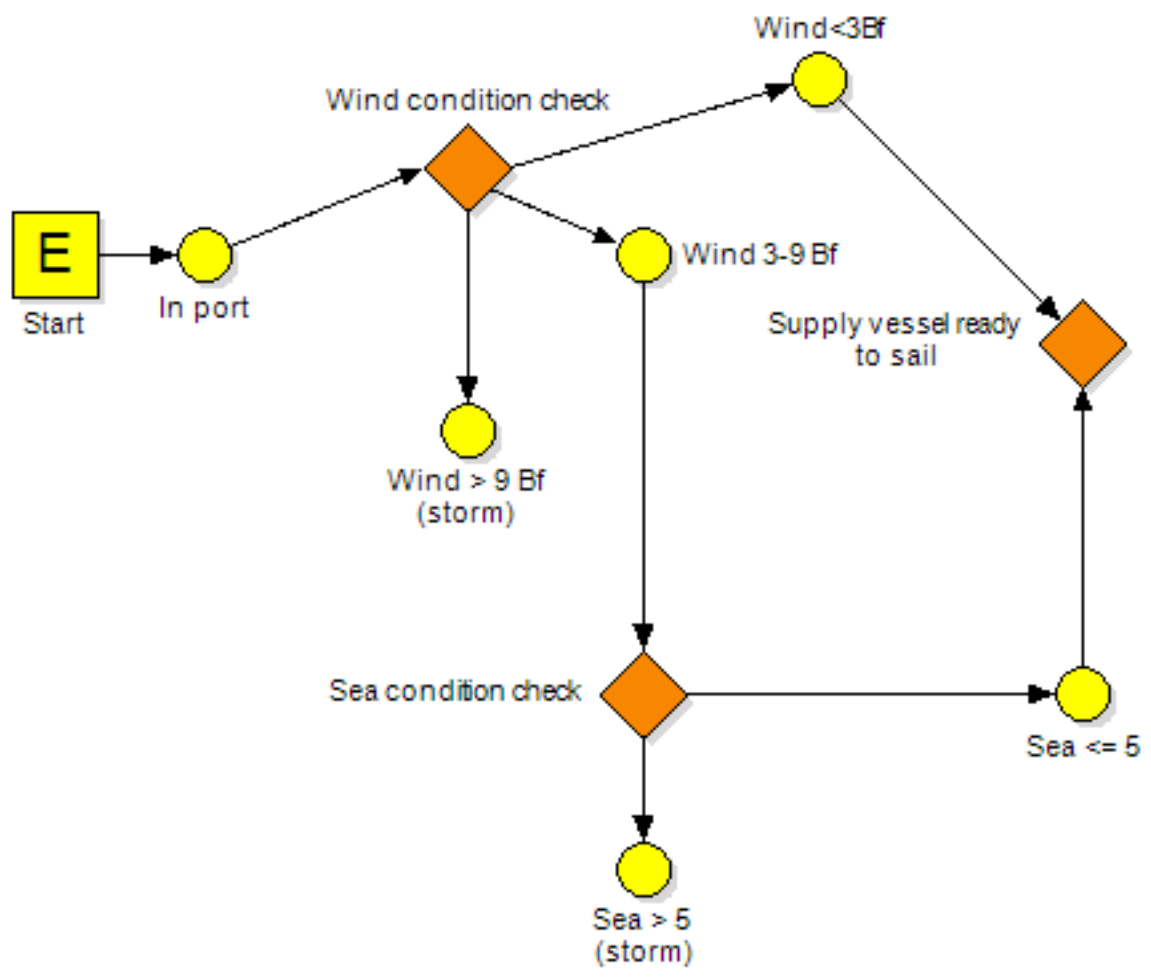

Figure 5. Model of the state of wind and waves before departure arcs Source: Author - Yasper

Navigation model and types of supply vessels

After checking the wind conditions, the event continues and we arrive at the process step "avigation to the platform" (Figure 6), where the time needed to sail to the platform and the consumption realized by the vessel on this trip are defined within the "timed" process step. The next process step is "Type of supply vessel", here it is selected whether the supply vessel is of AHTS or PSV type. Within the process step the number of vessels used in the model is entered as a percentage. 


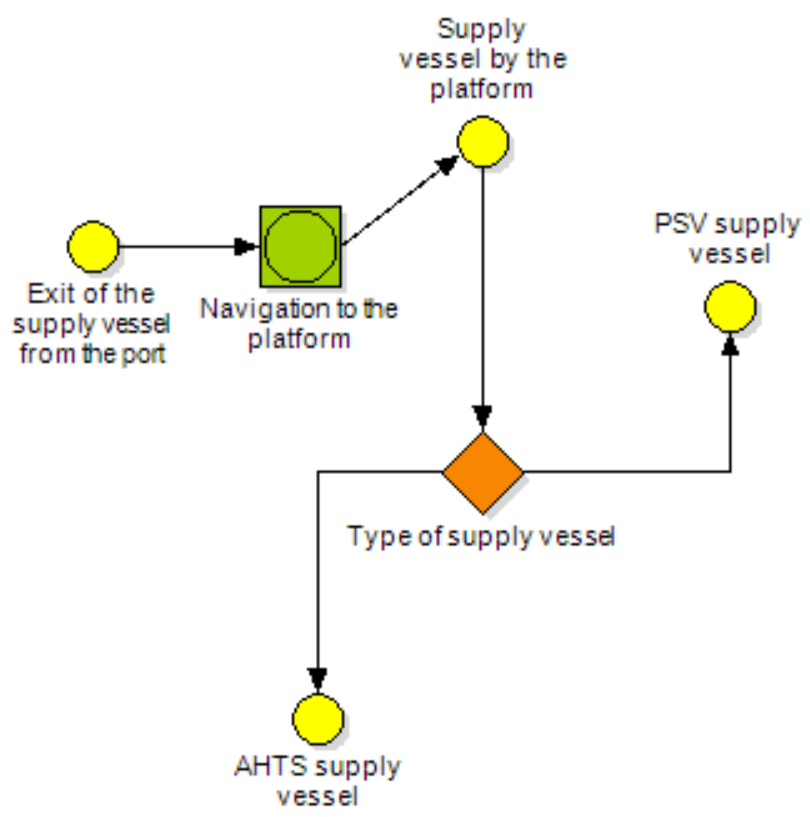

Figure 6. Navigation model and types of supply vessels Source: Author - Yasper

\section{PSV supply vessel operational model}

When an event is selected for the PSV vessel, we arrive at the process step "Sea condition near the platform" (Figure 7). Due to the sea state, the possibility of operating the PSV supply vessel below the platform will be checked. Within the process step "sea condition near the platform" the sea state is set in percentage and there are two places.

If the sea state is less than or equal to 5, the event continues to the process step "working with a crane under the platform". Within the process step, the consumption of the PSV supply vessel and the operating time are set and the event continues with the process step "Supply vessel ready to leave" and leaving the platform.

If the sea is greater than 5, we come to the process step "wind condition near the platform", where the wind state is set with percentage values and we have two places. If the place "wind is rising - possibility of a storm" is chosen, we go to the process step "leaving the platform" and leave the platform. The second place is "The wind is falling" and reaching the process step "Navigation near the platform", which determines the consumption and duration of navigation along the platform, and returning to the process step "Sea condition near the platform" in anticipation of the appropriate time to work under the platform. 


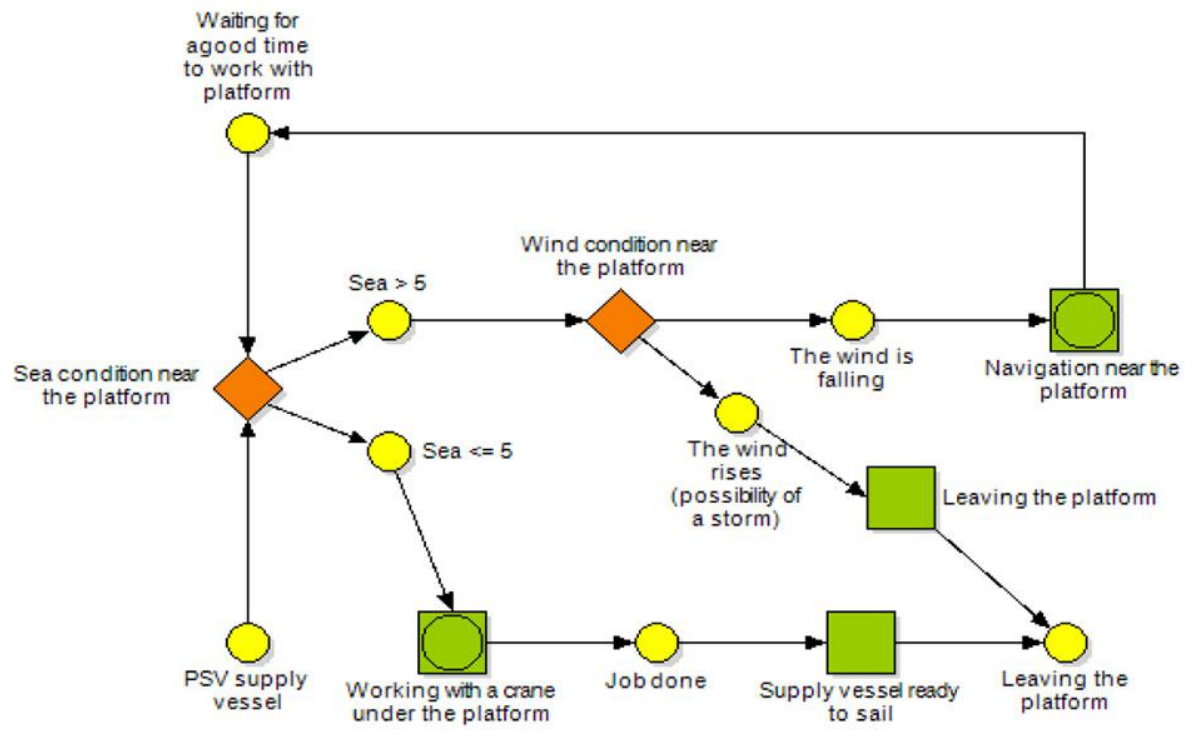

Figure 7. PSV supply vessel operational model arcs Source: Author - Yasper

\section{AHTS supply vessel operational model}

When an event is selected for the AHTS supply vessel, we arrive at the process step "Sea condition near the platform" (Figure 8). Due to the sea state, the possibility of operating the AHTS supply vessel below the platform will be checked. Within the process step "sea condition near the platform" the sea state is set in percent and there are two places.

If the sea is greater than 5, we come to the process step "wind condition near the platform", where the wind state is set with percentage values and we have two places. If the place "The wind is rising (possibility of a storm)" is chosen, we go to the process step "Leaving the platform" and leave the platform. The second place is "The wind is falling" and reaching the process step "Navigation near the platform", which determines the consumption and duration of navigation along the platform, and returning to the process step "Sea condition near the platform" in anticipation of the appropriate time to work under the platform.

If the sea is less than or equal to 5 , the event proceeds to the process step "type of work". Within the process step, the type of work for AHTS ships is determined by a percentage and we have two places. The first place is "platform supply" and arrival at the process step "Work with a crane under the platform", within which the consumption of the AHTS supply vessel and the time period for the work are determined. The event continues until the place "job done" and process step "Supply 
vessel ready to sail" and leaving the platform. The second place is "Moving the platform (work with anchors)", where we come to the process step "work with anchors from the platform", within which the consumption of the AHTS supply vessel and the time period for this type of work is specified. Further we go to the place "job done"and process step "Supply vessel ready to sail" and leaving the platform.

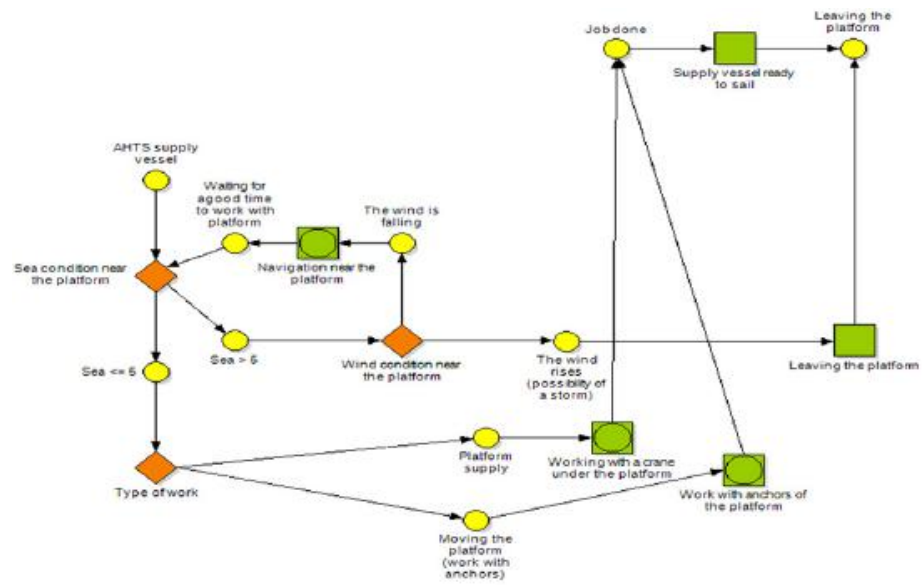

Figure 8. AHTS supply vessel operational modelarcs. Source: Author - Yasper

Number of vessels approaching the platform

Between the process step "Navigation to the platform" and the process step "Navigation to the harbour", a place with two tokens was set up, which controls

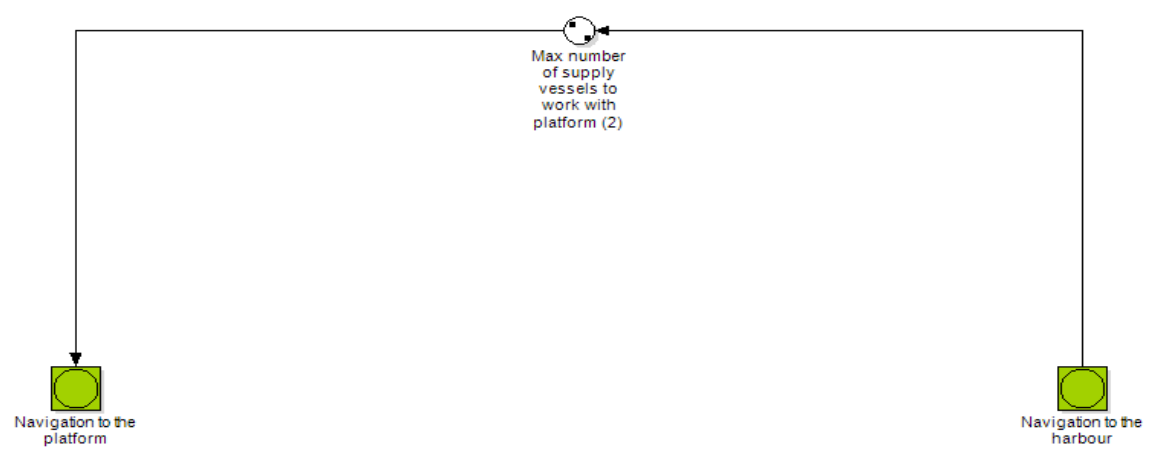

Figure 9. Number of vessels approaching the platform arcs

Source: Author - Yasper 
in the model that between these two process steps only a certain number of events is simulated at the same time (Figure 9). In this case we have worked with two "tokens", which means that only two cases can be in the model at the same time, corresponding to two supply vessels working under the platform. The number of tokens within the place can be entered according to the desired user models.

\section{Model of navigation from platform to harbour}

Upon completion of all process steps, regardless of the type of vessel and the work performed, all events occur in the process step "Navigation to harbour" where the time required to navigate to the harbour and the consumption of the vessel on this journey is determined (Figure 10). The last process step is "Supply vessel moored in harbour", after which the event ends in "Collector C".

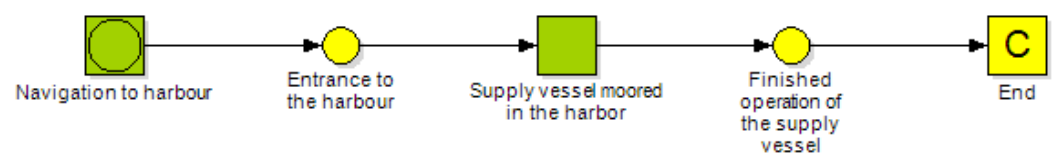

Figure 10. Model of navigation from platform to harbor arcs Source: Author - Yasper

\section{Results}

The model can be simulated manually or automatically. When an automatic simulation is taken, it can be determined in time, by the number of events sent or by the number of events completed. In this case, we took 240 time values (10 days) for the simulation (Figure 11).

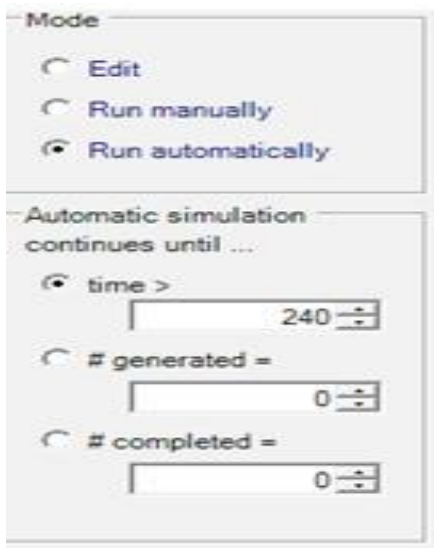

Figure 11. Capabilities of the simulation arcs. Source: Author - Yasper 
The simulation sent 61 events in 242 times and ran a simulation of 57 events. This showed that 4 events were not completed and 4 ships did not sail to the platform due to weather conditions (Figure 12).

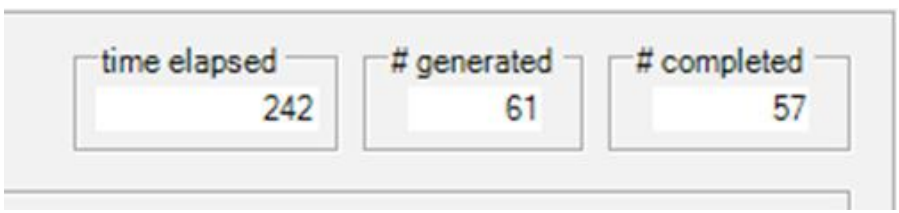

Figure 12. Results of generated and executed events arcs Source: Author - Yasper

By selecting an automatic simulation with time constraints, we obtained simulation results with data on how many events took place, how much time was spent on the whole event, counting the operation time and the waiting time for a given task (Figure 13). In this model, 57 events took place. Waiting time refers to the time spent by supply vessels in the waiting loop while other vessels are working under the platform, and operating time is the time spent working around the platform as well as navigating to the platform and navigating from the platform to harbour. Cost is the average value required for an event or trip from the port to the platform, for work there, and for return to the harbour. Cost is calculated based on the data entered in the process steps.

\begin{tabular}{lllll} 
conpleted & wallime & cycle ine & work bine & cost \\
\hline 57 & 2.04 & 9.02 & 6.98 & 439.16
\end{tabular}

Figure 13. Model simulation results arcs. Source: Author - Yasper

\section{Conclusions}

In this paper, we presented a model in Petri nets that simulates the operation process of supply ships. We have presented the model in a few steps to make the understanding of how the whole model works as simple as possible. Each of these smaller steps represents a smaller model that works separately, and together they make a complete model.

It is extremely important to fill in all process steps with correct data so that the results are as accurate as possible and so that the data is ultimately relevant to all subsequent steps in the supply ship business. Data on the sea state and wind, on the basis of which the events are constructed, are also important, because they give the opportunity to see how much the weather affects the process of navigation to the platform or the work around it. The numbers will 
be very different if the voyage takes place in rough and stormy seas than if the voyage takes place in a calm sea.

The daily rental rates of supply vessels are extremely high, and all users can easily use the model to get approximate figures that can help in the decision-making and price of renting supply vessels, both for vessel owners and oil companies renting supply vessels.

The plan is to develop the model further and try to develop a safer and better model to simulate the operation of supply vessels to help the industry, which has been in deep trouble in recent years. Data collection is underway and with their knowledge, there are plans to expand the model and conduct new research in this area.

\section{NOTES}

1. Jason Jiang, Splash247.com, Solstad Offshore secures AHTS contracts in Brazil, (June,2020) https://splash247.com/solstad-offshore-secures-ahts-contracts-inbrazil/

2. Golden energy offshore, fleet, "PSV EnergySwan", https://www.geoff.no/fleet/ energy-swan

3. MAERSK BROKER, AHTS \& PSV Market Overview Q3 2019

4. Clarkson Offshore Market Analysis, Market report Issue No. 58 - January 2021

5. Yasper User Guide, https://www.yasper.org/downloads/Yasper_User_Guide.pdf

\section{REFERENCES}

Ling, C., 2001. The Petri Net Method, School of Computer Science \& Software Engineering. Monash University.

Zurawsk, R., Zhou, M. C., 1994. Petri Nets and Industrial Applications: A Tutorial. In: IEEE Transactions on Industrial Electronics. 41(6), 567 - 583.

Camurri, A., Franchi, P., Gandolfo, F., Zaccaria, R., 1993. Petri net based process scheduling: A model of the control system of flexible manufacturing systems. Journal of Intelligent and Robotic Systems (8), $99-123$.

Reisig, W., Rozenberg, G., 1998. Lectures on Petri Nets 1, Basic Models. Springer-Verlag

Murata, T., 1989. Petri Nets: Properties, Analysis and Applications. Proc. IEEE 77, $541-580$

Jensen, K., 1997. Colored Petri Nets. Basic Concepts, Analysis Methods and Practical Use. Monographs in Theoretical Computer Science. Vol $1-3,2^{\text {nd }}$ corrected printing. Berlin: Springer-Verlag. 
Wang, J., 1998. Timed Petri Nets - Theory and Application. Boston, USA: Kluwer Academic Publishers.

\section{Toni Meštrović}

Faculty of Maritime Studies

University of Split Split, Croatia

E-mail: tmestrovic@pfst.hr $\square$ Danko Kezić
https://orcid.org/0000-0003-2055-8039
Faculty of Maritime Studies
University of Split
Split, Croatia
E-mail: danko.kezic@pfst.hr

$\triangle$ Ivica Pavić https://orcid.org/0000-0002-9087-3424

Faculty of Maritime Studies

University of Split Split, Croatia E-mail: ipavic71@pfst.hr

$\triangle$ Srđan Vukša https://orcid.org/0000-0003-3185-3308

Faculty of Maritime Studies

University of Split Split, Croatia E-mail:svuksa@pfst.hr 